Check for updates

Cite this: RSC Adv., 2017, 7, 38251

\title{
Glycerol hydrogenolysis over a Pt-Ni bimetallic catalyst with hydrogen generated in situ
}

\author{
Yuqiang Yan, ${ }^{\text {ab }}$ Yiying Zhang, ${ }^{a}$ Tao Jiang, ${ }^{a}$ Tiancun Xiao, ${ }^{b}$ Peter P. Edwards $\mathbb{D D}^{\mathrm{b}}$ \\ and Fahai $\mathrm{CaO}$ (D) *ac
}

Using hydrogen generated in situ from aqueous phase reforming provides an efficient and economic route for glycerol hydrogenolysis. A Pt-Ni bimetallic catalyst supported on $\gamma-\mathrm{Al}_{2} \mathrm{O}_{3}$ has been prepared to catalyze the selective hydrogenolysis of glycerol to 1,2-propanediol, with glycerol conversion reaching $71.4 \%$ in $3 \mathrm{~h}$. The significant promotion of conversion and selectivity could be explained by the formation of Pt-Ni alloy based on catalyst characterization. The effects of $\mathrm{Pt} / \mathrm{Ni}$ ratio, reaction temperature and reaction time on the conversion of glycerol as well as product selectivity were also investigated.

Received 23rd May 2017

Accepted 12th July 2017

DOI: 10.1039/c7ra05814d

rsc.li/rsc-advances

propanediol selectivity of $64 \%$ at $230{ }^{\circ} \mathrm{C}$ under atmospheric

\section{Introduction}

With its renewability, biodegradability and carbon neutrality, biodiesel is becoming an attractive energy resource as an alternative to fossil fuels. ${ }^{1}$ The past decade has seen the rapid development of the biodiesel industry, in which a great deal of glycerol is generated as a by-product from transesterification during biodiesel production (roughly $10 \mathrm{wt} \%$ of the feed oil or fat), but the demand for glycerol is so limited that extensive amounts of crude glycerol are disposed of by burning, which is a waste of potential organic raw materials and releases huge amounts of $\mathrm{CO}_{2} \cdot{ }^{2,3}$ Developing an economically attractive route to convert glycerol into high value-added chemicals, not only helps solve the glycerol surplus and cut down the production cost of the whole biodiesel industry, but also avoids wasting a carbon resource and diminishes the $\mathrm{CO}_{2}$ emission from burning.

Recent lots of attention has been paid to glycerol hydrogenolysis into diols such as 1,2-propanediol, 1,3-propanediol and ethylene glycol, which are widely used in the synthesis of pharmaceuticals, polymers, cosmetics, etc. ${ }^{4-8}$ However, the low solubility of molecular hydrogen in aqueous glycerol solutions requires a high hydrogen pressure to attain an acceptable conversion, which brings potential risks to industrial process and raises the production cost. D'Hondt et al. firstly reported an in situ hydrogenation route to produce 1,2-propanediol from glycerol, in which they used NaY zeolite supported Pt catalyst and achieved a glycerol conversion of $85.4 \%$ and a 1,2-

${ }^{a}$ Engineering Research Centre of Large Scale Reactor Engineering and Technology of Ministry of Education, East China University of Science and Technology, Shanghai 200237, China. E-mail: fhcao@ecust.edu.cn

${ }^{b}$ Inorganic Chemistry Laboratory, Department of Chemistry, University of Oxford, Oxford OX1 3QR, UK

${ }^{c}$ Key Laboratory of Coal Gasification and Energy Chemical Engineering of Ministry of Education, East China University of Science and Technology, Shanghai 200237, China conditions. ${ }^{9}$ Combining aqueous phase reforming and hydrogenolysis of glycerol (Fig. 1), the glycerol hydrogenolysis using hydrogen generated in situ no longer needs external hydrogen supply or hydrogen donor compounds, providing an efficient and economic route for glycerol hydrogenolysis.

Among various noble and base metals, Pt is the most selective catalyst for aqueous phase reforming of glycerol, but has a poor catalytic activity for glycerol hydrogenolysis. ${ }^{\mathbf{1 0 1 1}}$ The addition of second metal can strongly modify the activity and selectivity for the hydrogenolysis of glycerol. ${ }^{\mathbf{1 2 - 1 4}}$ Motivated by above considerations, in this paper a series of Pt-M ( $\mathrm{M}=\mathrm{Fe}, \mathrm{Co}$, $\mathrm{Ni}, \mathrm{Cu}, \mathrm{Zn}, \mathrm{Sn}$ ) bimetallic catalysts supported on $\gamma-\mathrm{Al}_{2} \mathrm{O}_{3}$ were prepared by incipient wetness impregnation technique, wherein Pt-Ni catalyst was selected because of its high catalytic activity and selectivity in glycerol hydrogenolysis. Field emission scanning electron microscope (FESEM), energy dispersive X-ray (EDX), X-ray diffraction (XRD), transmission electron microscopy (TEM), X-ray photoelectron spectroscopy (XPS), $\mathrm{N}_{2}$ adsorption/desorption and $\mathrm{H}_{2}$-temperature programmed reduction ( $\mathrm{H}_{2}$-TPR) were employed to examine the composition,

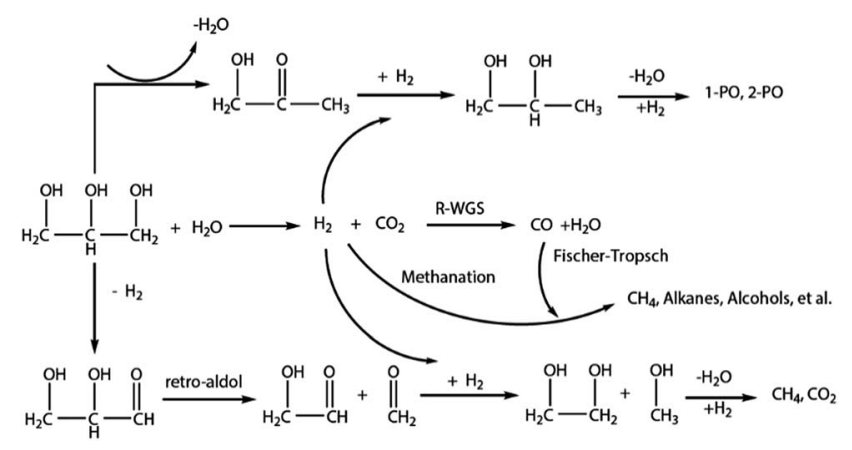

Fig. 1 The reaction network for glycerol hydrogenolysis using hydrogen generated in situ. 
structural and redox properties of the Pt-Ni catalyst. Then the effects of $\mathrm{Pt} / \mathrm{Ni}$ ratio, reaction temperature and reaction time on the conversion of glycerol as well as product selectivity were investigated in detail.

\section{Experimental}

\subsection{Catalyst preparation}

Pt-M (M = Fe, Co, Ni, Cu, Zn, Sn) bimetallic catalysts were prepared by incipient wetness impregnation technique. $\mathrm{H}_{2} \mathrm{PtCl}_{6} \cdot 6 \mathrm{H}_{2} \mathrm{O}$ and the nitrates of the second metal were dissolved in deionized water, then $\gamma-\mathrm{Al}_{2} \mathrm{O}_{3}$ support was added into the liquid phase and stirred till uniform. After impregnation, the sample was aged under room temperature overnight and then dried for $12 \mathrm{~h}$ at $100{ }^{\circ} \mathrm{C}$, followed by calcination in air for $4 \mathrm{~h}$ at $550{ }^{\circ} \mathrm{C}$. Before use, the catalyst was reduced at $500{ }^{\circ} \mathrm{C}$ for $4 \mathrm{~h}$ in a hydrogen flow at a steady rate of $50 \mathrm{~mL} \mathrm{~min}^{-1}$.

\subsection{Catalyst characterization}

The surface area and pore size were analysed by $\mathrm{N}_{2}$-adsorption/ desorption technique using a Micromeritics ASAP 2020 Physisorption. Typically, $0.2 \mathrm{~g}$ catalyst was placed in the sample tube and pre-treated for $6 \mathrm{~h}$ up to $300{ }^{\circ} \mathrm{C}$ at $133 \mathrm{~Pa}$ to remove the moisture and impurities adsorbed on the surface, then adsorption/desorption tests were performed in liquid nitrogen at $-196{ }^{\circ} \mathrm{C}$.

The chemical composition and morphology of the samples were determined by energy dispersive X-ray (EDX) attached to field emission scanning electron microscope (FESEM, Nova NanoSEM 450).

$\mathrm{X}$-Ray diffraction (XRD) patterns were obtained on a Rigaku $\mathrm{D} / \mathrm{max} 2550 \mathrm{X}$-ray diffractometer by using the $\mathrm{CuK} \alpha$ radiation $(\lambda=0.1544 \mathrm{~nm})$ and registered in the $2 \theta$ range of $10-80^{\circ}$ at a scan speed of $4^{\circ} \mathrm{min}^{-1}$.

The morphology of the metal nanoparticles was investigated by transmission electron microscopy (TEM) using JEOL-JEM 2100 electron microscope, operated at $200 \mathrm{kV}$. The samples were prepared using ethanol as the dispersant. An EDS analysis is attached to the TEM to determine the elemental distribution of the sample. XPS measurement was conducted by using an UIVAC-PHI 5000 Versaprobe with a monochromatic $\mathrm{Al} \mathrm{K} \alpha$ radiation.

$\mathrm{H}_{2}$-temperature programmed reduction $\left(\mathrm{H}_{2}\right.$-TPR) tests were performed with a Micromeritics AutoChemII2920 Chemisorption. A catalyst sample $(50 \mathrm{mg})$ was placed in a U-shaped quartz tube and pre-heated for $2 \mathrm{~h}$ at $300{ }^{\circ} \mathrm{C}$ in flowing argon, followed by cooling at room temperature. After the pre-treatment, the temperature was raised from room temperature to $800{ }^{\circ} \mathrm{C}$ in a $10 \% \mathrm{H}_{2} / \mathrm{Ar}$ mixture at a flow rate of $40 \mathrm{~mL} \min ^{-1}$, the $\mathrm{H}_{2}$ consumption was monitored with a thermal conductivity detector (TCD).

\subsection{Catalyst activity tests}

Glycerol hydrogenolysis reactions were carried out in a $250 \mathrm{~mL}$ stainless steel autoclave equipped with an electronic temperature controller and a mechanical stirrer. After loading the catalyst and glycerol into the autoclave, the reactor was purged with nitrogen at 2.0 MPa to remove air in it, then the system was pressurized with nitrogen to $1.0 \mathrm{MPa}$ and heated up to the reaction temperature. The rotation speed of the stirrer was set constantly at $500 \mathrm{rpm}$ throughout the reaction. At the end of the reaction, the reactor was cooled down to room temperature. The gas products were collected in a gas bag and analysed by gas chromatography equipped with a $3 \mathrm{~m}$ TDX-01 stainless column and a thermal conductivity detector. Liquid products were filtered to recover the solid catalyst powder and analysed by a gas chromatography equipped with a HP-INNOWAX column $(30 \mathrm{~m} \times 0.32 \mathrm{~mm} \times 0.25 \mu \mathrm{m})$ and a flame ionization detector. The conversion of glycerol and product selectivity were calculated using the following equations: $:^{15}$

$$
\text { Conversion }=\frac{\text { moles of glycerol consumed }}{\text { moles of glycerol initially charged }} \times 100 \%
$$

$$
\begin{aligned}
\text { Selectivity }= & \frac{\text { moles of carbon in specific product }}{\text { moles of carbon in all detected products }} \\
& \times 100 \%
\end{aligned}
$$

\section{Results and discussion}

\subsection{Catalyst screening}

Table 1 presents the conversion and product selectivity of glycerol hydrogenolysis at $240{ }^{\circ} \mathrm{C}$ for $3 \mathrm{~h}$ over $\mathrm{Pt}-\mathrm{M}(\mathrm{M}=\mathrm{Fe}, \mathrm{Co}$, $\mathrm{Ni}, \mathrm{Cu}, \mathrm{Zn}, \mathrm{Sn})$ bimetallic catalysts. Among the six bimetallic catalysts, Pt-Ni catalyst has the highest reaction conversion of $71.4 \%$, and gives a selectivity of $52.4 \%$ and $12.9 \%$ for 1,2 -propanediol (1,2-PDO) and ethylene glycol (EG) respectively.

\subsection{Catalyst characterization}

The specific surface area, pore volume and average pore diameter of the samples are summarized in Table 2. With the increment of $\mathrm{Ni}$ amount, the surface area and pore volume decrease due to the surface coverage and plugging of the pores by NiO. ${ }^{16}$ The $\mathrm{N}_{2}$ adsorption-desorption isotherms (Fig. 2a) reveal that all the $\mathrm{Pt}-\mathrm{Ni}$ bimetallic catalysts exhibit Type $\mathrm{V}$ isotherms with typical $\mathrm{H} 2$ hysteresis loops, which are characteristic of mesoporous materials. ${ }^{17}$ The pore diameter distribution shows that higher $\mathrm{Ni}$ amount leads to wider pore diameter distribution (Fig. 2b).

The morphological features of fresh and used Pt-Ni bimetallic catalyst were observed from FESEM analysis (Fig. 3). The fresh Pt-Ni catalyst has a high porosity and specific surface area, which offers more active sites and larger reaction zone for glycerol molecules. For the used catalyst, we found that the porous structure collapses and filamentous carbon species deposits on the surface. EDX analysis verified the formation of coke in the reaction, which leads to an increase of carbon content in the used catalyst (Fig. 4). It is also shown that the metal content on the catalyst surface rises slightly after reaction, which is explained by the agglomeration of metal 
Table 1 Glycerol hydrogenolysis over Pt-M bimetallic catalysts ${ }^{a}$

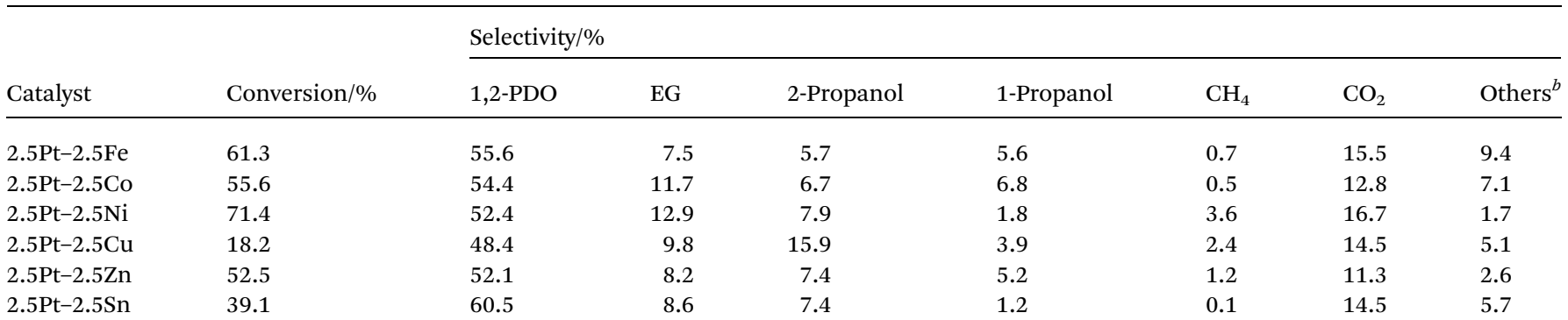

${ }^{a}$ Reaction conditions: $1.0 \mathrm{~g}$ of catalyst, $100 \mathrm{~mL}$ of glycerol aqueous solution $(20 \mathrm{wt} \%), 1.0 \mathrm{MPa}$ of $\mathrm{N}_{2}$ pressure, $240{ }^{\circ} \mathrm{C}$ of reaction temperature, $3 \mathrm{~h}$ of reaction time. ${ }^{b}$ Others contain methanol, ethanol, acetone alcohol, etc.

Table 2 Specific surface area, pore volume and average pore diameter

\begin{tabular}{llll}
\hline Catalysts & $\begin{array}{l}\text { Surface area } \\
\left(\mathrm{m}^{2} \mathrm{~g}^{-1}\right)\end{array}$ & $\begin{array}{l}\text { Pore volume } \\
\left(\mathrm{cm}^{3} \mathrm{~g}^{-1}\right)\end{array}$ & $\begin{array}{l}\text { Pore diameter } \\
(\mathrm{nm})\end{array}$ \\
\hline$\gamma-\mathrm{Al}_{2} \mathrm{O}_{3}$ & 235.2 & 0.47 & 8.0 \\
$2.5 \mathrm{Pt} / \gamma-\mathrm{Al}_{2} \mathrm{O}_{3}$ & 220.3 & 0.45 & 8.0 \\
$2.5 \mathrm{Pt}-1.0 \mathrm{Ni} / \gamma-\mathrm{Al}_{2} \mathrm{O}_{3}$ & 203.3 & 0.45 & 8.9 \\
$2.5 \mathrm{Pt}-2.5 \mathrm{Ni} / \gamma-\mathrm{Al}_{2} \mathrm{O}_{3}$ & 200.8 & 0.42 & 8.9 \\
$2.5 \mathrm{Pt}-5.0 \mathrm{Ni} / \gamma-\mathrm{Al}_{2} \mathrm{O}_{3}$ & 185.4 & 0.41 & 8.7 \\
& & &
\end{tabular}
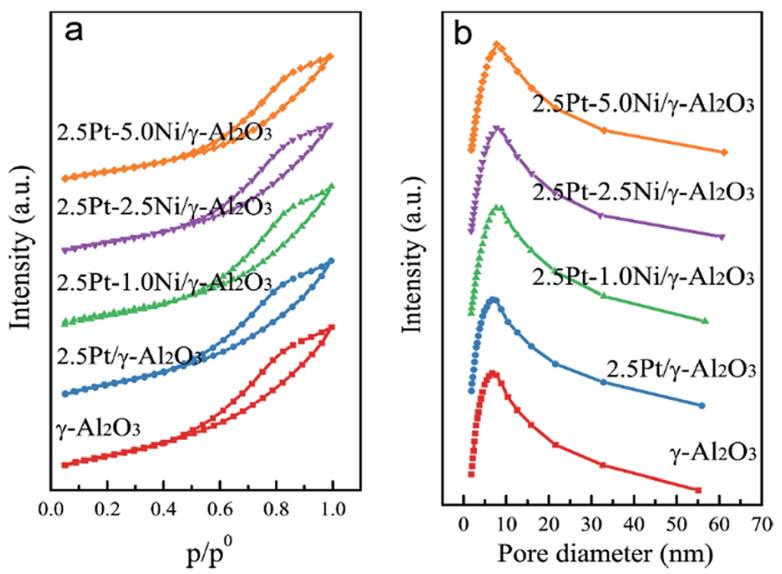

Fig. $2 \mathrm{~N}_{2}$ adsorption-desorption isotherms and pore diameter distribution.

particles. ${ }^{18}$ Both the coke formation and metal agglomeration contribute to deactivation of the catalyst.

XRD analyses were also conducted on unreduced and reduced catalysts. The peaks at $2 \theta$ values of $37.6^{\circ}, 45.9^{\circ}$ and $67.0^{\circ}$ are assigned to $\gamma-\mathrm{Al}_{2} \mathrm{O}_{3}$ support. As shown in Fig. 5a, XRD did not detect any platinum or nickel species on unreduced catalysts suggesting that the fine $\mathrm{PtO}_{2}$ and $\mathrm{NiO}$ particles are highly dispersed. XRD patterns of reduced catalysts are presented in Fig. 5b. Metallic Pt was observed at $39.6^{\circ}, 46.2^{\circ}$ and $67.3^{\circ}$ in reduced $2.5 \mathrm{Pt} / \gamma-\mathrm{Al}_{2} \mathrm{O}_{3}$ catalyst, which were attributed to the crystalline phases (111), (200), and (220), respectively. The peaks show a slight shift to higher $2 \theta$ value and lower intensity with an increase of $\mathrm{Ni}$ content after introducing $\mathrm{Ni}$ into the catalyst, indicating that $\mathrm{Ni}$ atoms have come into the Pt lattice. ${ }^{19}$ There was no noticeable peak for $\mathrm{Ni}$ metals in $2.5 \mathrm{Pt}-1.0 \mathrm{Ni} / \gamma-\mathrm{Al}_{2} \mathrm{O}_{3}$ catalyst and $2.5 \mathrm{Pt}-2.5 \mathrm{Ni} / \gamma-\mathrm{Al}_{2} \mathrm{O}_{3}$ catalyst, which suggests a high
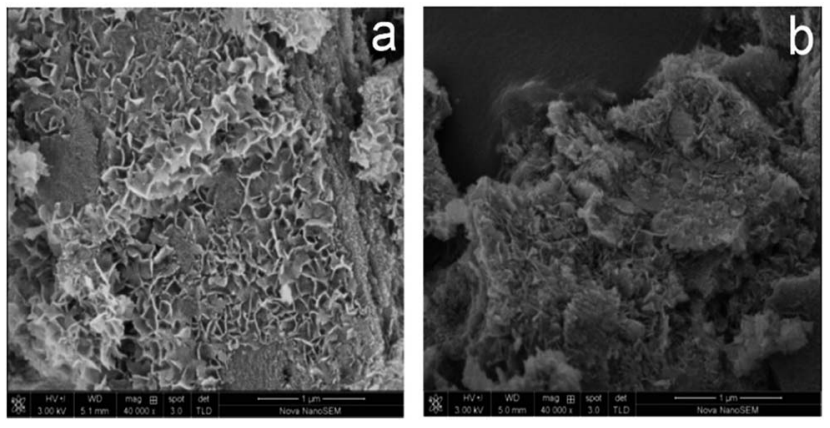

Fig. 3 FESEM images of $2.5 \mathrm{Pt}-2.5 \mathrm{Ni} / \gamma-\mathrm{Al}_{2} \mathrm{O}_{3}$ catalyst. (a) Fresh catalyst. (b) Used catalyst.

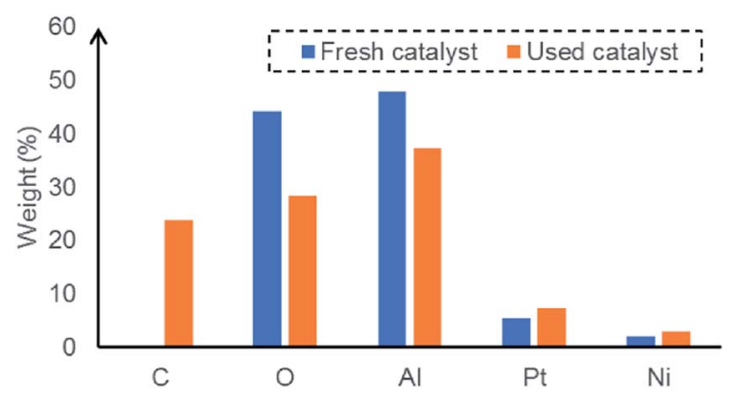

Fig. 4 EDX analysis of fresh and used $2.5 \mathrm{Pt}-2.5 \mathrm{Ni} / \gamma-\mathrm{Al}_{2} \mathrm{O}_{3}$ catalyst.
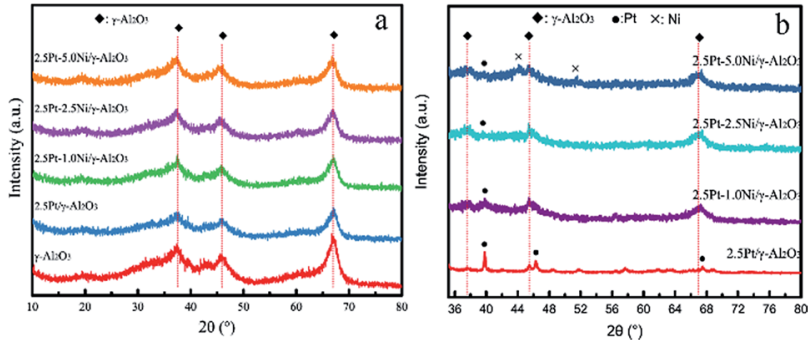

Fig. 5 XRD patterns of catalysts. (a) Unreduced catalyst. (b) Reduced catalyst. 
level of Pt-Ni alloys. ${ }^{20}$ Signals of Ni were detected with $2 \theta$ values of $44.5^{\circ}$ and 51.7 in $2.5 \mathrm{Pt}-5 \mathrm{Ni} / \gamma-\mathrm{Al}_{2} \mathrm{O}_{3}$ catalyst, which are indexed to the (111) plane and the (200) plane of face-centred cubic (fcc) Ni.

Fig. 6a presents a typical TEM image of the $2.5 \mathrm{Pt}-2.5 \mathrm{Ni} / \gamma-\mathrm{Al}_{2} \mathrm{O}_{3}$ catalyst. As can be seen, the Pt-Ni alloy nanoparticles spread out uniformly on the surface of $\gamma-\mathrm{Al}_{2} \mathrm{O}_{3}$ support, and the average measured particle diameter is approximately $1.9 \mathrm{~nm}$. EDS maps of $\mathrm{Pt}$ and $\mathrm{Ni}$ are presented in Fig. 6b and c, clearly revealing the locations of the nanoparticles. Although the two maps are not identical, there is a certain degree of correlation between the locations of Pt and Ni species. The loading amount of Pt : Ni obtained from spectral data is $2.05 \mathrm{wt} \%: 2.05 \mathrm{wt} \%$. Fig. 7 shows the XPS spectra of Pt $4 \mathrm{f}$ in reduced catalysts. The $\mathrm{Pt} 4 \mathrm{f}_{7 / 2}$ has a slight negative shift due to the transfer of electrons from Ni to Pt, which lowers the density of state on the Fermi level and subsequently improves the catalytic performance. ${ }^{21}$

$\mathrm{H}_{2}$-TPR profiles of calcined $\mathrm{Pt}-\mathrm{Ni}$ catalysts are shown in Fig. 8. Pt monometallic catalyst showed a reduction peak at $225{ }^{\circ} \mathrm{C}$ corresponding to the $\mathrm{PtO}_{2} \rightarrow$ Pt reduction. This peak had a shift towards lower temperature for Pt-Ni bimetallic catalyst, indicating that the addition of $\mathrm{Ni}$ promoted the reduction of Pt species, which may be explained by the formation of $\mathrm{Pt}-\mathrm{Ni}$ alloy. ${ }^{22}$ The reduction peak at the range of $600-$ $800{ }^{\circ} \mathrm{C}$ belongs to the reduction of $\mathrm{Ni}^{2+}$ ions incorporated in the nickel aluminate structure. ${ }^{23}$

\subsection{The effect of $\mathrm{Pt} / \mathrm{Ni}$ ratio}

The effect of $\mathrm{Pt} / \mathrm{Ni}$ ratio was investigated over $\mathrm{Pt}-\mathrm{Ni}$ bimetallic catalysts, and the glycerol conversion as well as product selectivity were presented in Table 3 . Results indicate that although
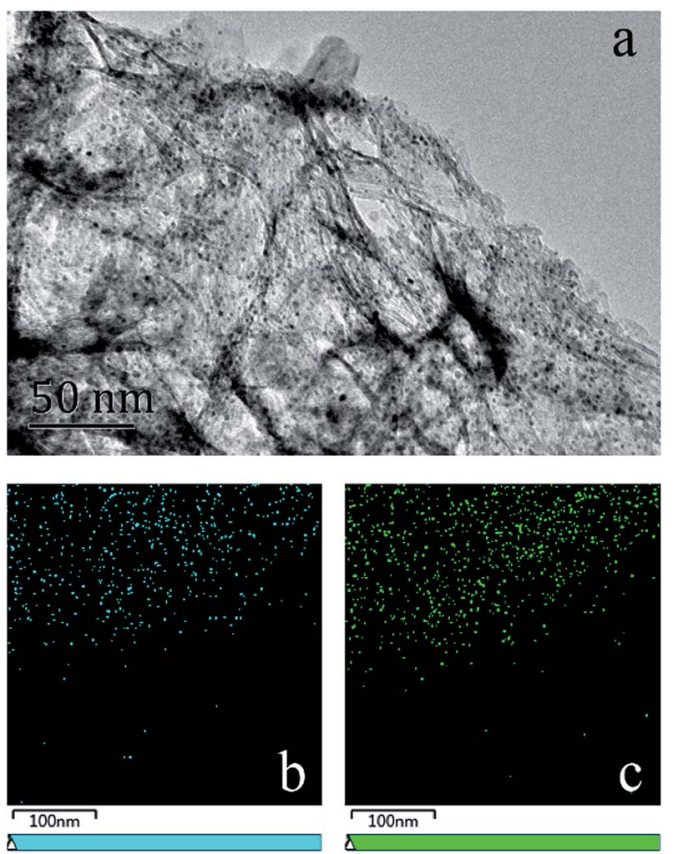

Fig. 6 (a) TEM image of $2.5 \mathrm{Pt}-2.5 \mathrm{Ni} / \gamma-\mathrm{Al}_{2} \mathrm{O}_{3}$ catalyst. (b) EDS map of Pt. (c) EDS map of $\mathrm{Ni}$.

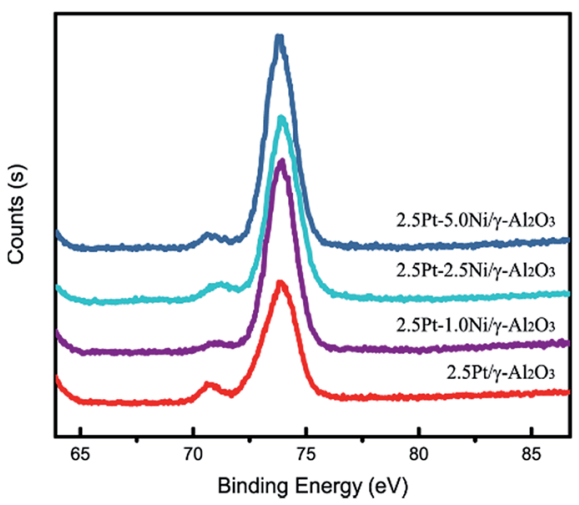

Fig. 7 XPS spectra of Pt $4 \mathrm{f}$ in the catalyst.

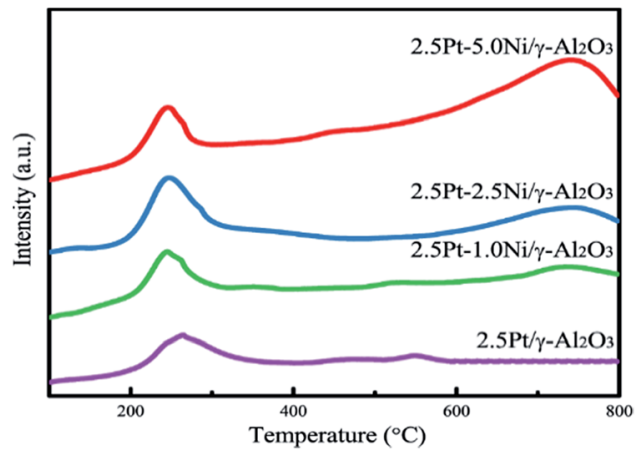

Fig. $8 \quad \mathrm{H}_{2}$-TPR profiles of calcined Pt-Ni catalysts.

glycerol hydrogenolysis reaction using hydrogen in situ generated is able to proceed over $\mathrm{Pt}-\mathrm{Al}_{2} \mathrm{O}_{3}$ catalyst, both the conversion and selectivity of 1,2-propanediol are relatively low. The addition of Ni significantly improves both the catalyst activity and selectivity for the hydrogenolysis of glycerol, which is associated with the strong interaction between $\mathrm{Pt}$ and $\mathrm{Ni}$ in the Pt-Ni catalyst, as evidenced in $\mathrm{H}_{2}$-TPR analysis. A maximum conversion was obtained at a $\mathrm{Pt} / \mathrm{Ni}$ ratio of $2.5: 2.5$. The surface area and pore diameter drop considerably with higher Ni content due to the plugging of $\mathrm{Ni}$ species, leading to a decline of catalyst activity. The selectivity of 1,2-propanediol also decreases owing to over-cracking of hydrogenolysis products into $\mathrm{CH}_{4}$ and $\mathrm{CO}_{2}$.

\subsection{The effect of reaction temperature}

The effect of reaction temperature on activity and selectivity was studied at a temperature range of $220-260{ }^{\circ} \mathrm{C}$, and the results are presented in Fig. 9. The glycerol conversion has an increasing trend with reaction temperature suggesting that temperature increment favours the reaction activity. The selectivity of 1,2-propanediol decreases from $61.7 \%$ at $220{ }^{\circ} \mathrm{C}$ to $37.3 \%$ at $260{ }^{\circ} \mathrm{C}$, caused by excessive hydro-deoxygenation of 1,2-propanediol ( $\mathrm{C}-\mathrm{O}$ and $\mathrm{C}-\mathrm{C}$ bond cleavage) to propanol and lower alcohols (i.e. methanol, ethanol). ${ }^{24-27}$ The selectivity of ethylene glycol also shows a decreasing trend, but the decrease is not significant. Lahr et al. found that ethylene glycol is considerably stable under hydrogenation reaction conditions, 
Table 3 Effect of Pt/Ni ratio on glycerol conversion and product selectivity ${ }^{a}$

\begin{tabular}{|c|c|c|c|c|c|c|c|c|}
\hline Catalysts & Conversion/\% & \multicolumn{7}{|c|}{ Selectivity/\% } \\
\hline $2.5 \mathrm{Pt}-1.0 \mathrm{Ni}$ & 65.0 & 56.9 & 10.6 & 7.8 & 5.2 & 1.3 & 15.9 & 2.3 \\
\hline $2.5 \mathrm{Pt}-2.5 \mathrm{Ni}$ & 71.4 & 52.4 & 10.9 & 7.9 & 1.8 & 1.6 & 16.7 & 1.7 \\
\hline $2.5 \mathrm{Pt}-5.0 \mathrm{Ni}$ & 66.2 & 50.9 & 13.1 & 9.2 & 4.0 & 1.9 & 15.8 & 2.1 \\
\hline
\end{tabular}

${ }^{a}$ Reaction conditions: $1.0 \mathrm{~g}$ of catalyst, $100 \mathrm{~mL}$ of glycerol aqueous solution ( $\left.20 \mathrm{wt} \%\right), 1.0 \mathrm{MPa}$ of $\mathrm{N}_{2}$ pressure, $240{ }^{\circ} \mathrm{C}$ of reaction temperature, $3 \mathrm{~h}$ of reaction time. ${ }^{b}$ Others contain methanol, ethanol, acetone alcohol, etc.

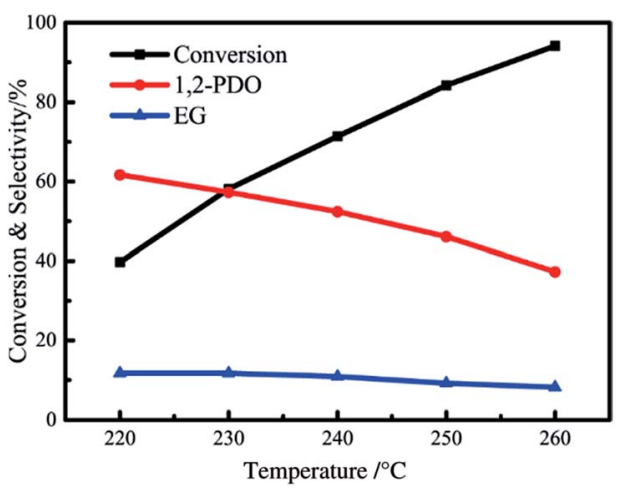

Fig. 9 Effect of reaction temperature on glycerol conversion and the selectivity of $1,2-\mathrm{PDO}$ and $\mathrm{EG}$ over $2.5 \mathrm{Pt}-2.5 \mathrm{Ni} / \gamma-\mathrm{Al}_{2} \mathrm{O}_{3}$ catalyst. Reaction conditions: $1.0 \mathrm{~g}$ of catalyst, $100 \mathrm{~mL}$ of glycerol aqueous solution (20 wt\%), 1.0 MPa of $\mathrm{N}_{2}$ pressure, $3 \mathrm{~h}$ of reaction time.

so the degradation of ethylene glycol is difficult to proceed in this reaction. ${ }^{28}$ Besides, the selectivity of gaseous product, $\mathrm{CH}_{4}$ and $\mathrm{CO}_{2}$, increases significantly with reaction temperature for aqueous phase reforming of glycerol is an endothermic reaction which favours a higher reaction temperature. ${ }^{10}$

\subsection{Reaction evolution with time}

The effect of reaction time was investigated over Pt-Ni catalyst, and the conversion of glycerol as well as product selectivity are

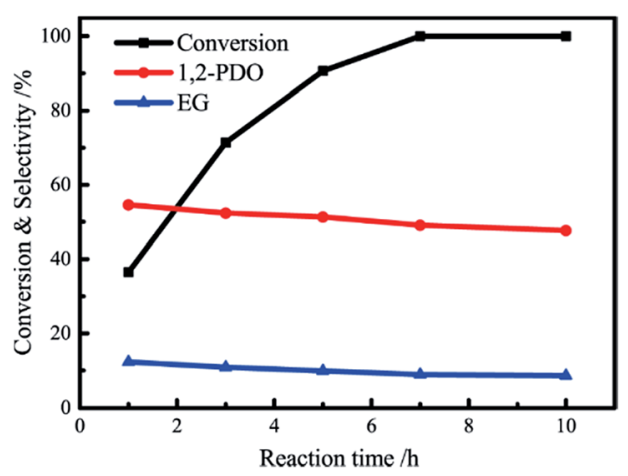

Fig. 10 Effect of reaction time on glycerol conversion and the selectivity of $1,2-\mathrm{PDO}$ and $\mathrm{EG}$ over $2.5 \mathrm{Pt}-2.5 \mathrm{Ni} / \gamma-\mathrm{Al}_{2} \mathrm{O}_{3}$ catalyst. Reaction conditions: $1.0 \mathrm{~g}$ of catalyst, $100 \mathrm{~mL}$ of glycerol aqueous solution (20 wt\%), $1.0 \mathrm{MPa}$ of $\mathrm{N}_{2}$ pressure, $240{ }^{\circ} \mathrm{C}$ of reaction temperature.

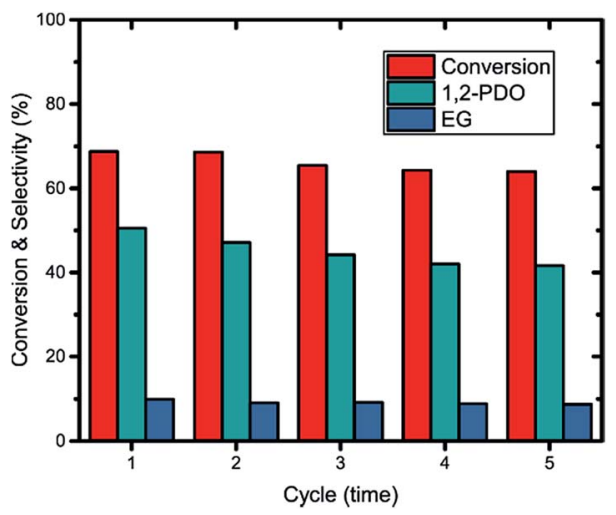

Fig. 11 Reusability tests over $2.5 \mathrm{Pt}-2.5 \mathrm{Ni} / \gamma-\mathrm{Al}_{2} \mathrm{O}_{3}$ catalyst. Reaction conditions: $1.0 \mathrm{~g}$ of catalyst, $100 \mathrm{~mL}$ of glycerol aqueous solution (20 wt\%), $1.0 \mathrm{MPa}$ of $\mathrm{N}_{2}$ pressure, $240{ }^{\circ} \mathrm{C}$ of reaction temperature, $3 \mathrm{~h}$ of reaction time.

illustrated in Fig. 10. Glycerol conversion grows rapidly in the beginning, reaching a high glycerol conversion of $71.4 \%$ at $3 \mathrm{~h}$ of reaction time, then it increases at a lower rate till a complete reaction for $7 \mathrm{~h}$. 1,2-Propanediol is formed with a high selectivity of $54.6 \%$ at $1 \mathrm{~h}$, which indicates the promotion on hydrogenation over Pt-Ni catalyst. The selectivity of 1,2-propanediol and ethylene glycol has a slight decrement with time due to catalytic cracking of 1,2-propanediol and ethylene into C1.

\subsection{Reusability of Pt-Ni catalyst}

Reusability tests were performed over $2.5 \mathrm{Pt}-2.5 \mathrm{Ni} / \gamma-\mathrm{Al}_{2} \mathrm{O}_{3}$ catalyst, wherein the catalyst was washed and recycled after each cycle. As can be seen in Fig. 11, both the conversion and the selectivity of 1,2-propanediol has a slight decrease after each cycle, which was caused mainly by the coke formation and metal agglomeration. The conversion of glycerol and the selectivity of 1,2-propanediol decreased by only $4.77 \%$ and $8.96 \%$ after 5 cycles, suggesting the good stability and reusability of the catalyst.

\section{Conclusions}

This paper demonstrates a hydrogenolysis process of glycerol using hydrogen generated from aqueous phase reforming in 
situ, which could proceed at a lower pressure and no longer need external hydrogen supply or hydrogen donor compounds. A series of $\mathrm{Pt}-\mathrm{M}$ ( $\mathrm{M}=\mathrm{Fe}, \mathrm{Co}, \mathrm{Ni}, \mathrm{Cu}, \mathrm{Zn}, \mathrm{Sn})$ bimetallic catalysts supported on $\gamma-\mathrm{Al}_{2} \mathrm{O}_{3}$ have been synthesized, wherein the Pt-Ni catalyst was studied in detail owing to its high catalytic activity and selectivity.

The presence of Pt-Ni alloy was revealed by our catalyst characterization results, leading to a significant promotion of the conversion and selectivity over $\mathrm{Pt}-\mathrm{Ni}$ bimetallic catalyst. A maximum conversion reached at a $\mathrm{Pt} / \mathrm{Ni}$ ratio of $2.5: 2.5$. Higher reaction temperature favours the reaction activity increase, but the selectivity of 1,2-propanediol decreases significantly caused by excessive hydro-deoxygenation of 1,2propanediol to propanol and lower alcohols. Glycerol conversion grows rapidly with reaction time initially, reaching $71.4 \%$ in $3 \mathrm{~h}$. The reusability tests examined the good stability of the catalyst.

\section{Acknowledgements}

This work was supported by the National Natural Science Foundation of China (21373083) and the Fundamental Research Funds for the Central Universities (222201717013 and 222201717004). Yuqiang Yan thanks for a scholarship from the China Scholarship Council.

\section{References}

1 G. Knothe and L. F. Razon, Prog. Energy Combust. Sci., 2017, 58, 36-59.

2 C. A. Quispe, C. J. Coronado and J. A. Carvalho Jr, Renewable Sustainable Energy Rev., 2013, 27, 475-493.

3 B. Katryniok, S. Paul, V. Bellière-Baca, P. Rey and F. Dumeignil, Green Chem., 2010, 12, 2079-2098.

4 S. Zhu, X. Gao, Y. Zhu and Y. Li, Green Chem., 2016, 18, 782791.

5 S. Zhu, X. Gao, Y. Zhu, Y. Zhu, H. Zheng and Y. Li, J. Catal., 2013, 303, 70-79.

6 P. Hirunsit, C. Luadthong and K. Faungnawakij, RSC Adv., 2015, 5, 11188-11197.

7 E. Vasiliadou, T. Eggenhuisen, P. Munnik, P. De Jongh, K. De Jong and A. Lemonidou, Appl. Catal., B, 2014, 145, 108-119.

8 J. B. Salazar, D. D. Falcone, H. N. Pham, A. K. Datye, F. B. Passos and R. J. Davis, Appl. Catal., A, 2014, 482, 137144.
9 E. D'Hondt, S. Van de Vyver, B. F. Sels and P. A. Jacobs, Chem. Commun., 2008, 6011-6012.

10 N. D. Subramanian, J. Callison, C. R. A. Catlow, P. P. Wells and N. Dimitratos, Int. J. Hydrogen Energy, 2016, 41, 1844118450.

11 I. Gandarias, P. L. Arias, J. Requies, M. B. Güemez and J. L. G. Fierro, Appl. Catal., B, 2010, 97, 248-256.

12 E. P. Maris, W. C. Ketchie, M. Murayama and R. J. Davis, J. Catal., 2007, 251, 281-294.

13 O. M. Daniel, A. DelaRiva, E. L. Kunkes, A. K. Datye, J. A. Dumesic and R. J. Davis, ChemCatChem, 2010, 2, 1107-1114.

14 M. L. Barbelli, G. F. Santori and N. N. Nichio, Bioresour. Technol., 2012, 111, 500-503.

15 T. Miyazawa, Y. Kusunoki, K. Kunimori and K. Tomishige, J. Catal., 2006, 240, 213-221.

16 I. Gandarias, J. Requies, P. L. Arias, U. Armbruster and A. Martin, J. Catal., 2012, 290, 79-89.

17 B. Mallesham, P. Sudarsanam, B. V. S. Reddy and B. M. Reddy, Appl. Catal., B, 2016, 181, 47-57.

18 S. Schimpf, C. Louis and P. Claus, Appl. Catal., A, 2007, 318, 45-53.

19 X. Peng, S. Zhao, T. J. Omasta, J. M. Roller and W. E. Mustain, Appl. Catal., B, 2017, 203, 927-935.

20 S. Lee, H. J. Kim, S. M. Choi, M. H. Seo and W. B. Kim, Appl. Catal., A, 2012, 429-430, 39-47.

21 P. K. Sahoo, B. Panigrahy and D. Bahadur, RSC Adv., 2014, 4, 48563-48571.

22 E.-Y. Ko, E. D. Park, K. W. Seo, H. C. Lee, D. Lee and S. Kim, Catal. Lett., 2006, 110, 275-279.

23 Z. Boukha, C. Jiménez-González, B. de Rivas, J. R. GonzálezVelasco, J. I. Gutiérrez-Ortiz and R. López-Fonseca, Appl. Catal., B, 2014, 158, 190-201.

24 J. Yuan, S. Li, L. Yu, Y. Liu and Y. Cao, Chin. J. Catal., 2013, 34, 2066-2074.

25 M. Balaraju, V. Rekha, P. S. Prasad, R. Prasad and N. Lingaiah, Catal. Lett., 2008, 126, 119-124.

26 C.-J. Yue, L.-P. Gu, Y. Su and S.-P. Zhu, React. Kinet., Mech. Catal., 2014, 111, 633-645.

27 L. Guo, J. Zhou, J. Mao, X. Guo and S. Zhang, Appl. Catal., A, 2009, 367, 93-98.

28 D. G. Lahr and B. H. Shanks, J. Catal., 2005, 232, 386-394. 